\title{
Effect Evaluation and Influencing Factors of E-learning Training in Colleges
}

\author{
https://doi.org/10.3991/ijet.v16i22.26877
}

Li Zhou

Hebei Finance University Library, Baoding, China

zhouli202109@126.com

\begin{abstract}
E-learning is a teaching model formed during the informatization of colleges. It is of great significance to the promotion of teaching reform. This paper tries to evaluate the training effect of e-learning among college students, understand their perception and expectation of e-learning, and demonstrate the importance of the training to the practical ability and professional knowledge utilization of college students. In addition, the factors affecting e-learning training in colleges are evaluated one by one. The results show that e-learning training effect can be assessed well with an evaluation index system (EIS), consisting of a response layer, a learning layer, a behavior layer, and a result layer. The training effect of e-learning is influenced by the trainee characteristics, working environment, and training design. The research lays a theoretical basis for applying elearning training in teaching.
\end{abstract}

Keywords - e-learning, informatization, teaching reform, training effect, influencing factors

\section{Introduction}

With the development and prosperity of the information industry, an increasing number of training programs choose to apply the e-learning form, which has greatly improved the development efficiency of human resources $[1,2]$. E-learning is a practical teaching model and teaching philosophy formed in colleges and universities for the purpose of better adapt to social development state and economic forms [3]. Applying e-learning among college students is a necessary work for higher educational schools to deepen their educational reform, and an important means for them to improve the quality of cultivated talents and to promote the development of higher education in China $[4,5]$. Judging from a strategic point of view, implementing e-learning is a necessity for education in the long run, and it is of great significance for the development of higher educational schools [6].

In recent years, China is requiring higher education to develop towards the direction of networked and digitized, and the government is vigorously promoting e-learning training programs in colleges and universities, which can effectively promote the development of higher education disciplines, strengthen the construction of curriculum for innovation and entrepreneurship education, and contribute to establishing a multi- 
layer and three-dimensional education curriculum system [7, 8]. College students nowadays generally have good innovation ability, and promoting e-learning in the innovation and entrepreneurship education in colleges can greatly motivate their enthusiasm to start their own businesses [9]. The purpose of carrying out e-learning training programs for college students is to better trigger the professional education and social practice of college students, and exert their potential in innovation and knowledge learning $[10,11]$. The evaluation of training effect is the most direct and important measure that reflects whether a training program is useful or not, so it is meaningful for research on training effect evaluation [12]. Through the research on the training effect of e-learning and the evaluation of the training effect of online teaching, we can figure out whether the innovation awareness and professionalism of college students who have participated in the training could be motivated, whether their learning enthusiasm could be aroused, and whether the curriculum setting and teaching methods could meet the requirements of the training programs $[13,14]$.

Although people have fully aware of the importance of e-learning, until now, there isn't a systematic or complete training program system for students in colleges, and there's no targeted evaluation for these training programs [15]. The work blank in this aspect will make the feedback of these e-learning training programs lag behind, resulting in that the training effect of e-learning programs has been greatly reduced [16]. In view of these matters, this paper attempts to figure out college students' perception and expectation of e-learning by investigating their evaluation on the training effect of elearning, so as to better explore the important role of college student training in enhancing their practical ability and professional knowledge utilization, and better evaluate the influencing factors of e-learning in colleges.

\section{Situations and problems with college e-learning}

\subsection{Current situations}

Taking the innovation programs of college students as an example, according to the e-learning training content, the innovation and entrepreneurship education of college students can be divided into four modules: awareness education, knowledge ability education, environment cognition education, and practice education [17, 18]. The programs aim to cultivate students' knowledge learning ability and good psychological quality [19], and the use of e-learning is to enable students to better adapt to the reform and social development trend. The training effect evaluation is to measure and reflect the effect of e-learning training programs, and to figure out the its functions $[20,21]$. The training effect evaluation needs to apply scientific theories, methods, and operating procedures to the training process, and connect the collected data and training requirements with the training goals to better determine the feasibility, practical value, and effect of the training programs [22].

Figure 1 gives the flow of the training process when college students use e-learning for the innovation and entrepreneurship programs. First, the training objectives are determined and the training needs are analyzed, then, the courses are designed and the 
training courses are taught. With a college student innovation and entrepreneurship research program as an example, to conduct e-learning training, three parts of content should be clarified, namely the innovation training program, the entrepreneurship training program, and the entrepreneurship practice program; then, work links are completed one by one, including: design the innovative research program, write business plan, apply for major innovative research program, and participate in innovation and entrepreneurship competition.

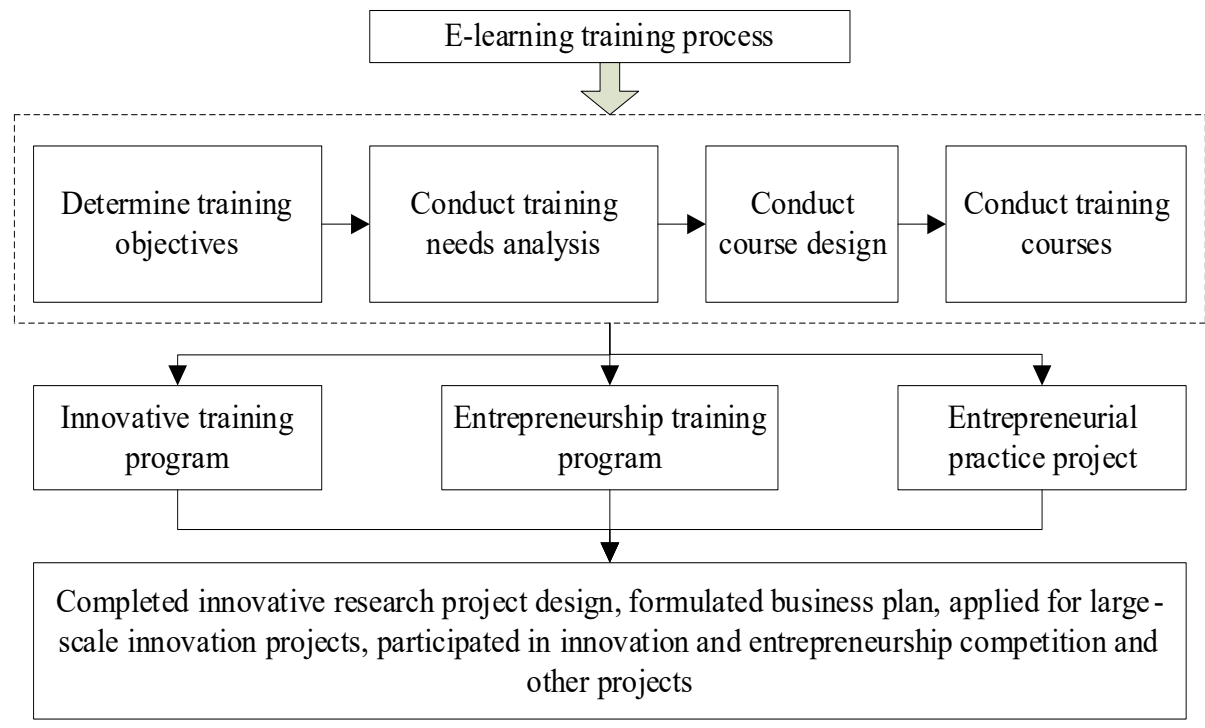

Fig. 1. Flow of training process when college students use e-learning for innovation and entrepreneurship programs

\subsection{Problems}

There are a variety of evaluation models for e-learning training, including the Kirkpatrick four-level evaluation model, the return-on-investment model, and the background-input-process-outcome model, etc. [23-25], among which the return-on-investment model is the most commonly-used model, as shown in Figure 2, the model contains three main steps: develop evaluation plan, analyze training data, and give optimization suggestions. The evaluation plan is formulated based on the collected basic data and training effect data, then the training data is analyzed to obtain the training effect evaluation, after that, the data is converted, the return on investment is calculated, and the intangible earnings are determined; at last, the impact of the training is determined, and the report is prepared.

This section takes the e-learning of innovation and entrepreneurship programs as an example to provide a good training platform for college students, through e-learning training, students could get more knowledge and skills, therefore, it is the basis for college students to carry out the programs $[26,27]$. However, in terms of curriculum 
setting, faculty resource, and infrastructure construction, e-learning is still at an initial stage and requires improvement and systematization. Figure 3 summarizes problems in the e-learning training in colleges. First, the current curriculum plan and system are flawed, there're too few professional skill courses for innovation and entrepreneurship education, and the existing courses are incomplete, narrow-span, and immaturely structured. Second, the faculty resource for full-time training is insufficient, there're too few teachers with online education and training quality, the schools should equip the training programs with more professional and excellent teachers who are qualified for innovation and entrepreneurship education. Third, the construction of laboratories and other facilities is not in place, many disciplines need to exercise students' practical operation ability, without a good venue, the training effect will be greatly reduced. Fourth, students do not pay enough attention to e-learning, they participate in it perfunctorily. At last, there isn't a mechanism for follow-up evaluation after the training programs, so for whether the e-learning training has met the expected requirements and objectives or not, it lacks effective feedback.

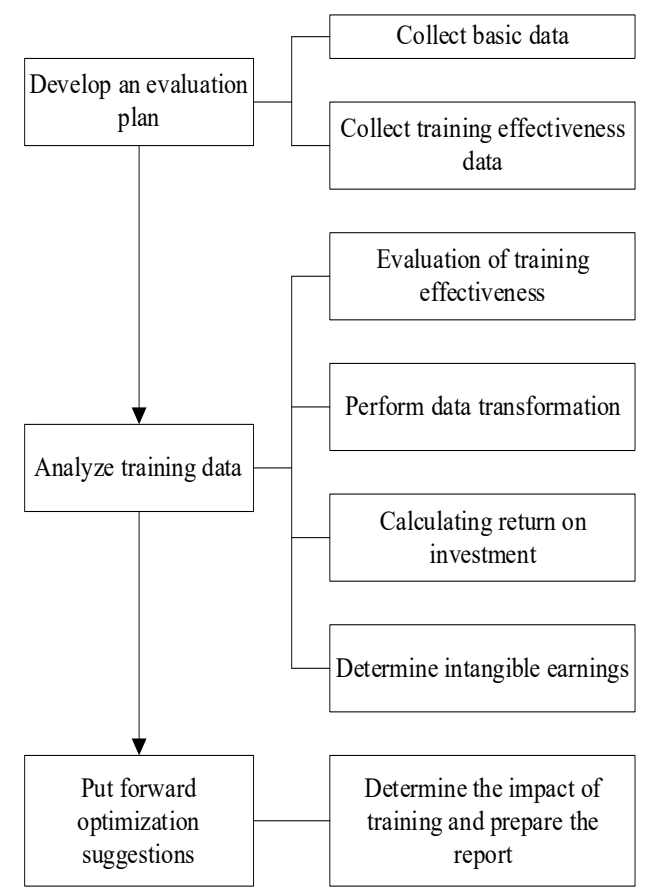

Fig. 2. The return-on-investment model 


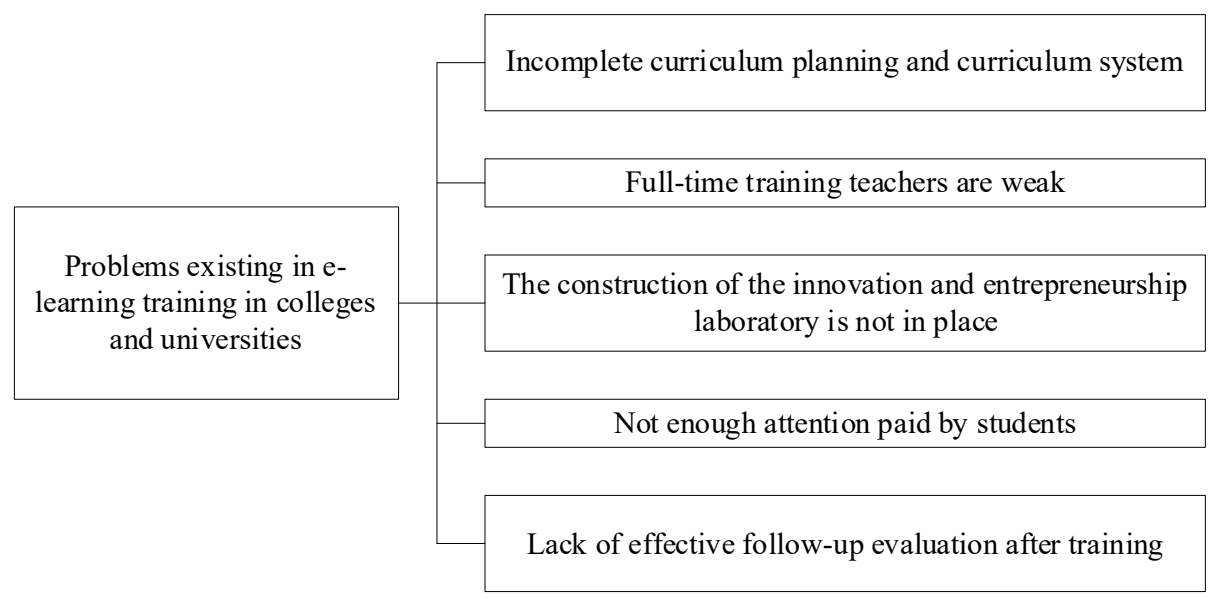

Fig. 3. Problems in the e-learning training in colleges

\section{$3 \quad$ EIS construction and evaluation}

\subsection{EIS construction}

The training effect of e-learning programs should be counted based on the data before and after the training, and then analyzed qualitatively or quantitatively. To ensure the validity of the evaluation, certain principles must be followed when constructing the EIS, as summarized in Figure 4, including the objective principle, scientific principle, integral principle, value principle, practical principle, and the principle of combining qualitative and quantitative evaluations. Figure 5 shows the structure of the proposed EIS for the training effect of e-learning. In the designed structure, first-level indexes include the response layer, learning layer, behavior layer, and result layer, wherein the response layer contains four second-level indexes: curriculum setting, training teacher, training content, and training method; the learning layer contains three second-level indexes: theoretical knowledge, thinking mode, and skill mastery; the behavior layer contains three second-level indexes: learning attitude, learning ability, and learning efficiency; the result layer contains four second-level indexes: organizational ability, innovative spirit, satisfaction, and result efficiency. 


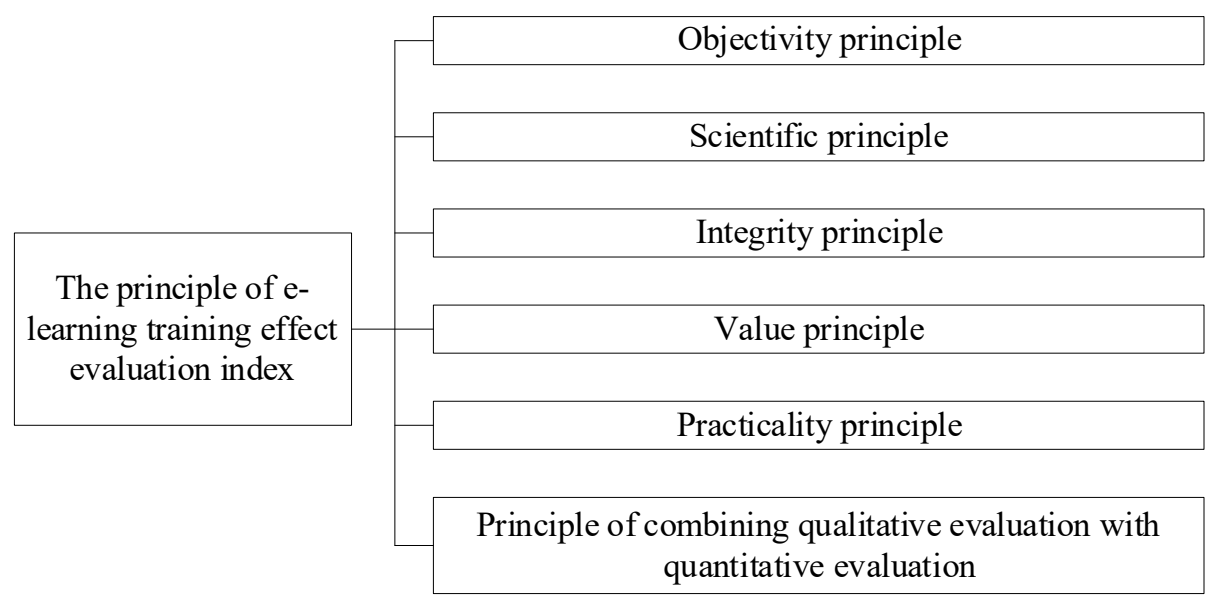

Fig. 4. Principles for EIS construction

Indexes in the response layer are the basic guarantees required by the training programs, the curriculum setting mainly stipulates the course types, categories, arrangement sequence, and class hour distribution, etc. Teachers engaging in e-learning training programs should have a wealth of theoretical knowledge and practical experience, they should make full preparations for the training programs, have a serious and rigorous attitude, and interact with students actively. The training content should be properly selected in a targeted manner, and enable students to know the relevant knowledge easily and efficiently, students can choose training methods and means such as case study, on-site investigation, and role play; the training plan should be well formulated, the training courses should be well selected, and the training methods should be able to meet the training objectives and training requirements. In the learning layer, the evaluation is a measure of the learning effect of trainees, it mainly examines their theoretical knowledge, thinking, and skills. The behavior layer reflects the changes in the behavior of trainee students before and after the training, such as their learning enthusiasm and enterprising spirit, as well as the learning attitude, ability, and efficiency. The result layer is the evaluation of trainees' performance in innovation and entrepreneurship after the e-learning training and their satisfaction with the training programs. 


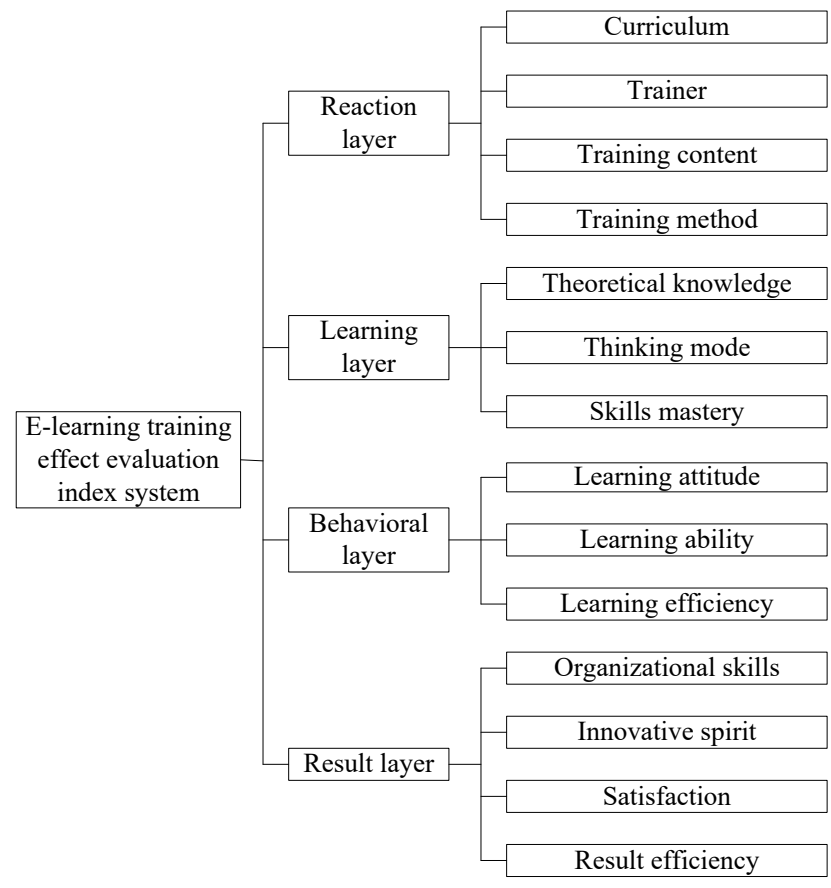

Fig. 5. Structure of the proposed EIS

\subsection{E-learning training effect evaluation}

To turn the subjective and theoretical EIS into an objective and practical one, this study empirically screened the evaluation indexes to improve the reliability and validity of the EIS, and to make the evaluation indexes more scientific, reasonable, and rigorous. A questionnaire survey was conducted to score the indexes in the four layers. Figure 6 shows the evaluation results of the E-learning training effect. Figure 6(a) shows the training effect evaluation results of the response layer. Respondents who think the curriculum setting is very good or good accounted for more than 50\%; more than $20 \%$ of the trainees think the curriculum is poorly or very poorly set; more than $60 \%$ of the trainees rated the teachers as very good, while training teachers who were rated as poor or very poor accounted for $14 \%$; more than $70 \%$ of the trainees rated the training materials as very good or good; and more than $70 \%$ of the trainees evaluated the training methods to be very good or good. Figure 6(b) is the training effect evaluation results of the learning layer. In terms of the learning layer, more than $70 \%$ of the respondents rated the theoretical knowledge and thinking mode to be very good or good; and only less than $10 \%$ think they are poor. Figure 6(c) shows the training effect evaluation results of the behavior layer. More than $65 \%$ of the trainees evaluated the learning attitude to be very good or good; the proportion of respondents evaluated the learning ability to be very good or good is close to $40 \%$, and this number is $48 \%$ in case of learning efficiency. Figure 6 (d) shows the training effect evaluation results of the result layer. The satisfaction of trainees is relatively high, followed by innovative spirit, organizational 
ability, and result efficiency. In terms of the four indexes in this layer, more than $90 \%$ of the trainees believe that the training effect is acceptable.

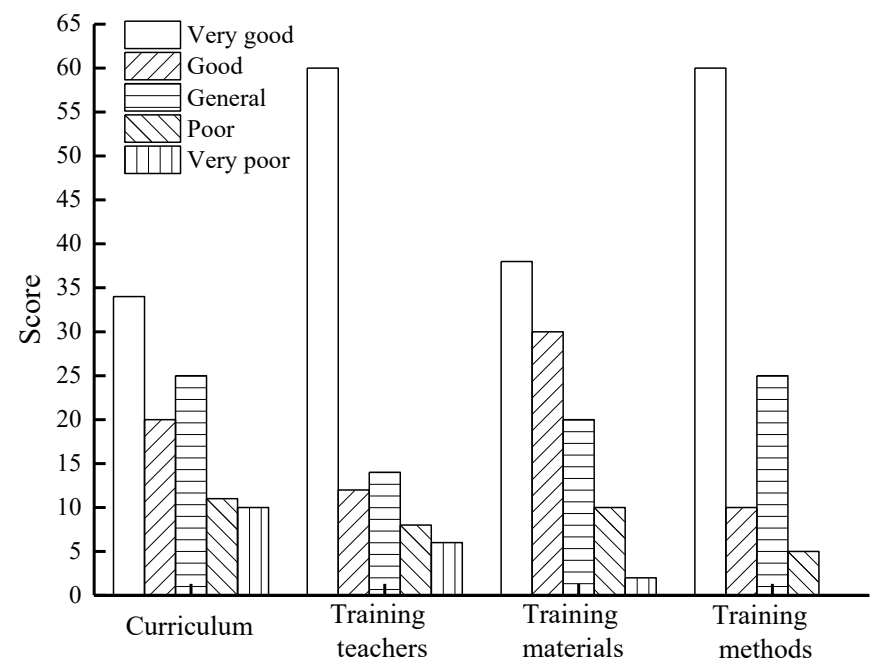

a) Training effect evaluation results of the response layer

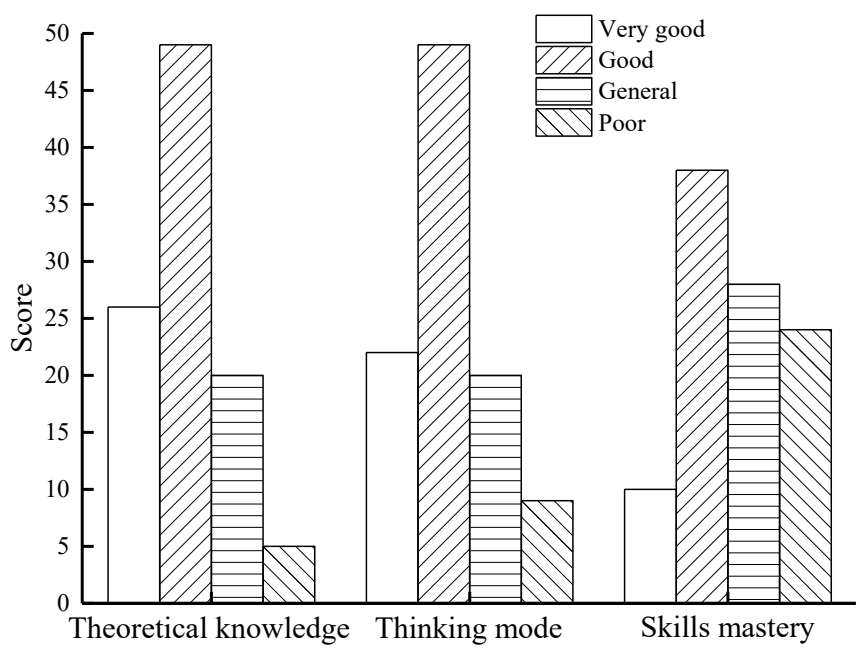

b) Training effect evaluation results of the learning layer 


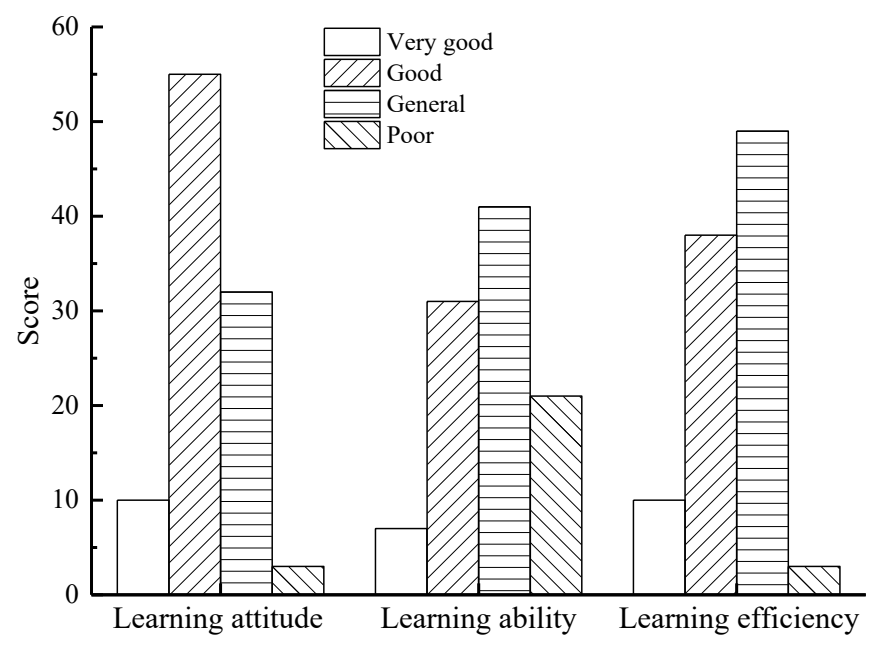

c) Training effect evaluation results of the behavior layer

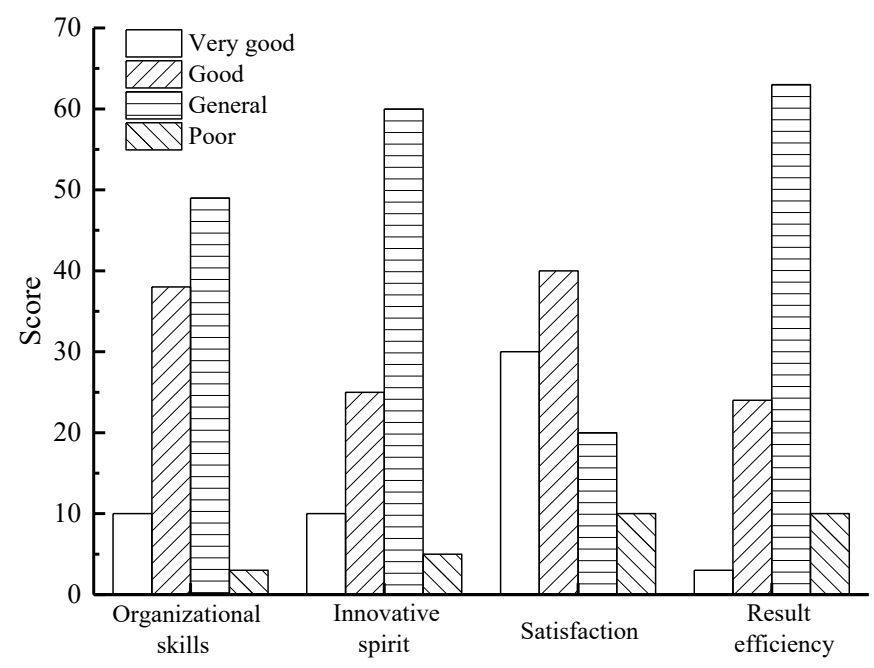

d) Training effect evaluation results of the result layer

Fig. 6. Evaluation results of e-learning training effect

\section{Influencing factors of e-learning training effect}

Only after clarifying the influencing factors of e-learning training effect can the factors in each link be controlled during the training, so that the positive factors could exert their greatest effects and the best training effect could be guaranteed [28, 29]. In the third section, the text gives the e-learning training effect EIS, in the proposed system, 
the response layer is the satisfaction degree of trainees; the learning layer measures the learning gain of trainees; the behavior layer examines the knowledge utilization of the trainees; and the result layer calculates the benefits created by the training [30, 31]. Figure 7 lists the influencing factors of e-learning training effect, including the trainee characteristics, the working environment, and the training design. According to the actual situations of e-learning training, the factor of trainee characteristics is divided into two variables: learner motivation and self-efficacy; the factor of working environment is divided into two variables: training support and atmosphere transformation; the factor of training design is divided into four variables: analysis design, curriculum development, teaching implementation, and training evaluation.

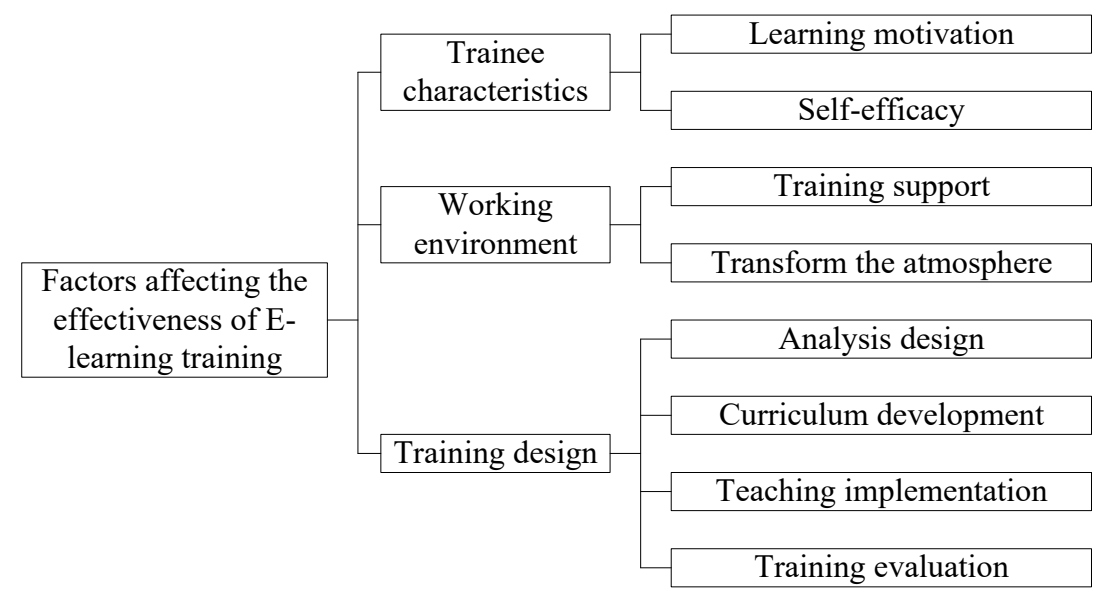

Fig. 7. Influencing factors of e-learning training effect

\section{Countermeasures for improving e-learning training effect}

Nowadays, MOOC technology, online platforms, information processing techniques, and audio-visual equipment have been widely applied; in order to improve the teaching quality of colleges and universities, carrying out e-learning training has become a specific manifestation of the structural reform of the supply-side in education [32]. Figure 8 lists the countermeasures proposed in this paper for improving the elearning training effect. First, we must strengthen the understanding and attention to training evaluation, give comprehensive evaluation to e-learning training effect, and fully promote the smooth implementation of the e-learning training effect evaluation works. Second, we should improve the quality of the trainers, starting from the trainers, we need to do a good job in cultivating the trainers, prioritize the training of trainers, and enhance their ability and quality. Third, we could set up special training effect evaluation and management organizations, and perform the work via these different organizations, the management and organization system should at least include a training observer group, a training research group, and a training effect evaluation group. 
Fourth, we should optimize the human resource management and performance appraisal system, look for fair and just performance appraisers, determine reasonable performance standards, strengthen performance communication and performance feedback, and implement different performance appraisal principles after long-term testing and adjustment. Fifth, we could establish a feedback mechanism for the evaluation of e-learning training effect. Sixth, we could establish a dynamic improvement and promotion mechanism for the evaluation of e-learning training effect.

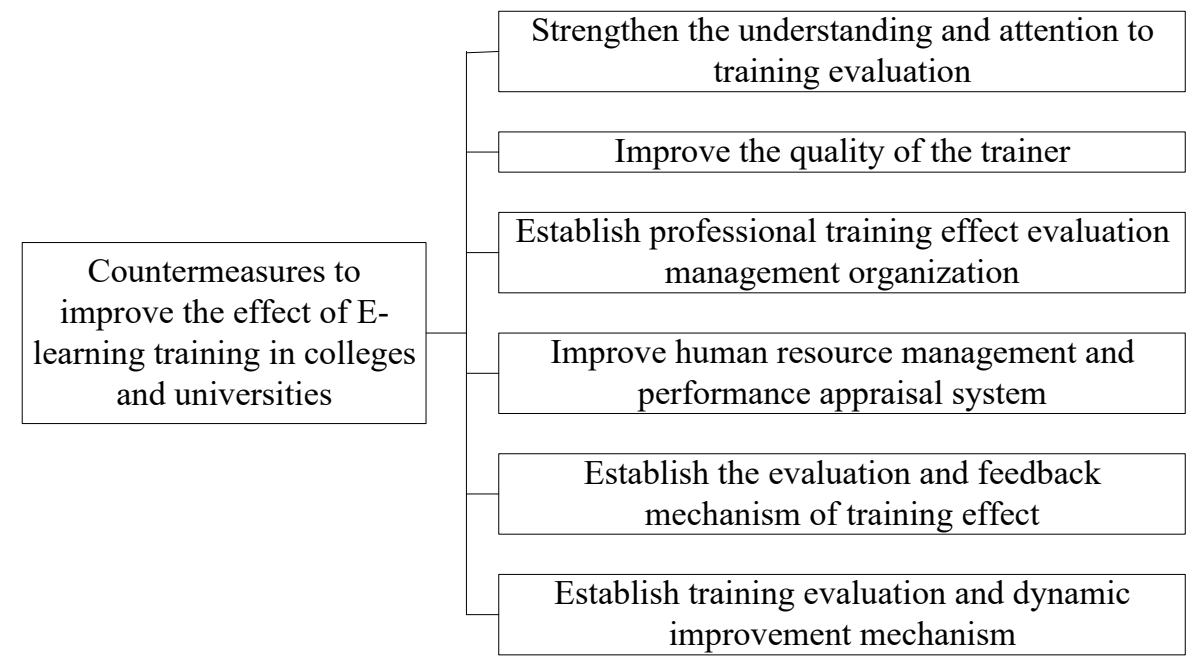

Fig. 8. Countermeasures for improving the e-learning training effect in colleges

\section{Conclusions}

This paper explored the evaluation of the training effect of e-learning programs for college students, figured out their perception and expectation of e-learning, demonstrated the importance of the training to the practical ability and professional knowledge utilization of college students, and the analyzed the influencing factors of the training effect of e-learning in colleges. The specific conclusions are:

1. The evaluation indexes chosen for the evaluation of the training effect of e-learning should follow the objective principle, scientific principle, integral principle, value principle, practical principle, and the principle of combining qualitative and quantitative evaluations.

2. This paper proposed an EIS for the evaluation of the training effect of e-learning that contains a response layer, a learning layer, a behavior layer, and a result layer. Indexes in the response layer are the basic guarantees required by the training programs; the evaluation of the learning layer is a measure of the learning effect of trainees; the behavior layer mainly reflects the changes in the behavior of trainee 
students before and after the training; and the result layer is the evaluation of trainees' performance in innovation and entrepreneurship after the e-learning training and their satisfaction with the training programs.

3. Influencing factors of e-learning training effect include the trainee characteristics, the working environment, and the training design. The factor of trainee characteristics is divided into two variables of learner motivation and self-efficacy; the factor of working environment is divided into two variables of training support and atmosphere transformation; and the factor of training design is divided into four variables of analysis design, curriculum development, teaching implementation, and training evaluation.

\section{$7 \quad$ References}

[1] Khlifi, Y. (2020). An Advanced Authentication Scheme for E-evaluation Using Students Behaviors Over E-learning Platform, International Journal of Emerging Technologies in Learning, 15(4), 90-111. https://doi.org/10.3991/ijet.v15i04.11571

[2] Shannon, C., Stebbing, P. D., Quinn, C. H., Warren, D. A., Dunn, A. M. (2020). The effectiveness of e-learning on biosecurity practice to slow the spread of invasive alien species. Biological Invasions, 22(8): 2559-2571. https://doi.org/10.1007/s10530-02002271-Z

[3] Meredith, P., Yeates, H., Greaves, A., Taylor, M., Slattery, M., Charters, M., \& Hill, M. (2018). Preparing mental health professionals for new directions in mental health practice: Evaluating the sensory approaches e-learning training package. International journal of mental health nursing, 27 (1): 106-115. https://doi.org/10.1111/inm.12299

[4] Magruder, K. M., York, J. A., Knapp, R. G., Yeager, D. E., Marshall, E., Desantis, M. (2006). Rct evaluating provider outcomes by suicide prevention training modality: in-person vs. e-learning. Journal of Mental Health Training, Education and Practice, 10(4): 207-217. https://doi.org/10.1108/jmhtep-09-2014-0028

[5] Maertens, H., Madani, A., Landry, T., Vermassen, F., Van Herzeele, I., Aggarwal, R. (2016). Systematic review of e-learning for surgical training. Journal of British Surgery, 103(11): 1428-1437. https://doi.org/10.1002/bjs. 10236

[6] Jimenez, J. E., O'Shanahan, I. (2016). Effects of web-based training on Spanish pre-service and in-service teacher knowledge and implicit beliefs on learning to read. Teaching and Teacher Education, 55: 175-187. https://doi.org/10.1016/j.tate.2016.01.006

[7] Flynn, S., Hastings, R. P., McNamara, R., Gillespie, D., Randell, E., Richards, L., Taylor, Z. (2019). Who's Challenging Who? a co-produced approach for training staff in learning disability services about challenging behaviour. Tizard Learning Disability Review. 24(4): 192-199. https://doi.org/10.1108/tldr-03-2019-0013

[8] Morente, L., Morales-Asencio, J. M., Veredas, F. J. (2014). Effectiveness of an e-learning tool for education on pressure ulcer evaluation. Journal of clinical nursing, 23(13-14): 20432052. https://doi.org/10.1111/jocn. 12450

[9] Hjorth-Johansen, E., Hofoss, D., Kynø, N. M. (2019). E-learning or lectures to increase knowledge about congenital heart disease in infants: A comparative interventional study. Nursing open, 6(3): 1143-1149. https://doi.org/10.1002/nop2.317

[10] De La Garza, J. R., Kowalewski, K. F., Friedrich, M., Schmidt, M. W., Bruckner, T., Kenngott, H. G., Nickel, F. (2017). Does rating the operation videos with a checklist score 
improve the effect of E-learning for bariatric surgical training? Study protocol for a randomized controlled trial. Trials, 18(1): 1-10. https://doi.org/10.1186/s13063-017-1886-7

[11] Lund, E., Schuele, C. M. (2014). Effects of a word-learning training on children with cochlear implants. Journal of Deaf Studies and Deaf Education, 19(1): 68-84. https://doi.org/10.1093/deafed/ent036

[12] Peters, S., Barbier, M., Faulx, D., Hansez, I. (2012). Learning and motivation to transfer after an e-learning programme: impact of trainees' motivation to train, personal interaction and satisfaction. Innovations in Education and Teaching International, 49(4): 375-387. https://doi.org/10.1080/14703297.2012.728878

[13] Zhang, W., Cheng, Y. L. (2012). Quality assurance in e-learning: PDPP evaluation model and its application. International Review of Research in Open and Distributed Learning, 13(3): 66-82. https://doi.org/10.19173/irrodl.v13i3.1181

[14] Wijaya, M.C., Maksom, Z., Abdullah, M.H.L. (2021). A brief of review: Multimedia authoring tool attributes. Ingénierie des Systèmes d'Information, 26(1): 1-11. https://doi.org/ $\underline{10.18280 / \text { isi.260101 }}$

[15] Pineda-Herrero, P., Belvis, E., Moreno, V., Duran-Bellonch, M. M., Úcar, X. (2011). Evaluation of training effectiveness in the Spanish health sector. Journal of Workplace Learning., 23(5): 315-330. https://doi.org/10.1108/13665621111141911

[16] Langton, E. K., Miguel, C. F., Diaz, J. E., Cordeiro, M. C., Heinicke, M. R. (2020). An evaluation of matrix training to teach college students piano notes and rhythms. Journal of applied behavior analysis, 53(3): 1466-1484. https://doi.org/10.1002/jaba.690

[17] Lang, F. K., Randles, C. A., Jeffery, K. A. (2020). Developing and evaluating a graduate student teaching assistant training course in the chemistry department of a large American university. Journal of Chemical Education, 97(6): 1515-1529. https://doi.org/10.1021/ acs.jchemed.9b00686

[18] Cheng, X. (2014). A Novel Probe into College English Qualityoriented Transformation Based on the Impersonal Evaluation Criteria of College English Instruction. Theory \& Practice in Language Studies, 4(4): 736-742. https://doi.org/10.4304/tpls.4.4.736-742

[19] Megheirkouni, M., Roomi, M. A. (2017). Women's leadership development in sport settings: Factors influencing the transformational learning experience of female managers. European Journal of Training and Development, 41(5): 467-484. https://doi.org/10.1108/ EJTD-12-2016-0085

[20] Wang, F. K., Schwen, T. (2003). Organizational Factors that Influence E-learning Development and Implementation in the Corporate Context. Performance Improvement Quarterly, 16(3): 64-86. https://doi.org/10.1111/j.1937-8327.2003.tb00288.x

[21] Lai, H. J. (2011). The influence of adult learners' self-directed learning readiness and network literacy on online learning effectiveness: a study of civil servants in Taiwan. Journal of Educational Technology \& Society, 14(2): 98-106.

[22] Bausch, S., Michel, A., Sonntag, K. (2014). How gender influences the effect of age on selfefficacy and training success. International Journal of Training and Development, 18(3): 171-187. https://doi.org/10.1111/ijtd.12027

[23] Hardison, D. M. (1999). Bimodal speech perception by native and nonnative speakers of English: Factors influencing the McGurk effect. Language Learning, 49: 213-283. https://doi.org/10.1111/0023-8333.49.s1.7

[24] Stanhope, D. S., Pond III, S. B., Surface, E. A. (2013). Core self-evaluations and training effectiveness: Prediction through motivational intervening mechanisms. Journal of Applied Psychology, 98(5): 820. https://doi.org/10.1037/a0032599

[25] Schmidt, J. R., De Houwer, J. (2012). Contingency learning with evaluative stimuli. Experimental Psychology. 59(4): 175-182. https://doi.org/10.1027/1618-3169/a000141 
[26] Ikram, U. Z., Essink-Bot, M. L., Suurmond, J. (2015). How we developed an effective elearning module for medical students on using professional interpreters. Medical Teacher, 37(5): 422-427. https://doi.org/10.3109/0142159X.2014.939579

[27] Tchernegovski, P., Reupert, A., Maybery, D. (2015). "let's talk about children": a pilot evaluation of an e-learning resource for mental health clinicians. Clinical Psychologist, 19(1): 49-58. https://doi.org/10.1111/cp.12050

[28] Brydges, R., Manzone, J., Shanks, D., Hatala, R., Hamstra, S. J., Zendejas, B., Cook, D. A. (2015). Self-regulated learning in simulation-based training: a systematic review and metaanalysis. Medical education, 49(4): 368-378. https://doi.org/10.1111/medu.12649

[29] Mittal, M. (2008). Evaluating perceptions on effectiveness of e-learning programs in Indian banks: identifying areas for improvement. Development \& Learning in Organizations, 22(2): 12-14. https://doi.org/10.1108/14777280810850679

[30] Mackey, E., Dodd, K. (2011). Evaluation and effectiveness of pain recognition and management training for staff working in learning disability services. British Journal of Learning Disabilities, 39(3): 243-251. https://doi.org/10.1111/j.1468-3156.2010.00661.x

[31] Antonis, K., Daradoumis, T., Papadakis, S., Simos, C. (2010). Evaluation of the effectiveness of a web-based learning design for adult computer science courses. IEEE Transactions on Education, 54(3): 374-380. https://doi.org/10.1109/TE.2010.2060263

[32] Mungania, P., Hatcher, T. (2004). A systemic, flexible, and multidimensional model for evaluating e-learning programs. Performance Improvement, 43(7): 33-39. https://doi.org/10. $\underline{1002 / \text { pfi. } 4140430710}$

\section{Author}

Li Zhou was born in 1975 and has a bachelor's degree. She works in the library of Hebei Finance University as an associate research librarian. Her research interests include reader service, reading promotion and library digital construction, and has published more than 10 academic papers.

Article submitted 2021-09-09. Resubmitted 2021-10-10. Final acceptance 2021-10-12. Final version published as submitted by the author. 